\title{
MATERIALIDADES DO TEXTO: UM PERCURSO HISTÓRICO
}

\author{
Aline Leal Fernandes Barbosa ${ }^{1}$
}

\begin{abstract}
RESUMO: Este artigo focalizará a questão da materialidade do texto e dos seus suportes, indissociável das suas condições de produção, transmissão e recepção. Para abordá-la, colocaremos em diálogo o pensamento de Jacques Rancière e de Roger Chartier. A primeira parte do mito platônico do Fedro será considerada no sentido de ressaltar a dupla crítica que é feita à escrita: ser ao mesmo tempo muda e falante demais, e trata de uma nostalgia da presença, da letra órfã à procura de um pai, de um corpo em que encarnar. Chartier, por sua vez, confere ênfase às transformações das práticas de leitura no percurso do rolo ao códice e na mais recente revolução que consistiria no novo suporte representado pelas telas.
\end{abstract}

PALAVRAS-CHAVE: Escrita. Suporte. Materialidade. Autor.

\begin{abstract}
"A impossibilidade de delimitação entre uma noção comum e o conceito específico de uma coisa definida não é um defeito atribuível às imperfeições da língua ou ao atraso do conceito. "Literatura" é um desses nomes flutuantes que resistem à redução nominalista, um desses conceitos transversais que têm a propriedade de desmanchar as relações estáveis entre nomes, ideias e coisas e, junto com elas, as delimitações organizadas entre as artes, os saberes ou os modos do discurso".
\end{abstract}

Jacques Rancière, em Políticas da escrita

Escrito há vinte e cinco séculos, o diálogo platônico Fedro é ainda frequentemente evocado pelo pensamento ocidental para tratar da escrita. A passagem escolhida é aquela em que Sócrates narra o momento no qual o deus Thoth apresenta sua nova invenção ao faraó egípcio Tamuz: "Esta arte, caro rei, tornará os egípcios mais sábios e Ihes fortalecerá a memória; portanto, com a escrita inventei um grande auxiliar para a memória e a sabedoria." Exaltada por Thoth, a nova técnica é, por sua vez, repelida por Tamuz: "Tu, como pai da escrita, esperas dela com o teu entusiasmo precisamente o contrário do que ela pode fazer." Segundo o faraó, a escrita tornará os homens esquecidos, pois ao confiar nos livros se lembrarão de um assunto apenas exteriormente e por meio de sinais, e não por si mesmos. A escrita

\footnotetext{
${ }^{1}$ Doutoranda do programa de pós-graduação em Literatura Cultura e Contemporaneidade do departamento de Letras da Pontifícia Universidade Católica do Rio de Janeiro. Imeio: alinelfbarbosa@gmail.com
} 
é perigosa porque põe em risco o dom maior do homem - sua memória - levando esquecimento à sua alma.

Embora pareça irônico que Platão apresentasse por escrito sua acusação contra a escrita, ele pretendia reproduzir o discurso de Sócrates, que não escrevia, sob a forma de diálogo com Fedro. Nele, o faraó manifesta um "medo eterno", como colocou Umberto Eco em Não contem com o fim dos livros, de que uma nova tecnologia seja capaz de abolir algo que é considerado precioso e superior. A escrita era perigosa porque diminuía o poder da mente, oferecendo aos seres humanos uma alma petrificada, uma caricatura da mente, uma memória mineral.

Sócrates segue sua crítica no diálogo com Fedro ao sugerir que a escrita arquitetaria uma disjunção entre o discurso e o seu autor, sem o qual o primeiro não pode se proteger nem se defender. O discurso vivo e animado, por sua vez, além de defender a si mesmo, sabe diante de quem convém falar e diante de quem é preferível ficar calado. Nas palavras que Platão atribui a Sócrates, este seria o "irmão legítimo" da "eloquência bastarda" do outro, evidenciando a condição órfã do escrito sem pai. A escrita, simulacro, é também por essa razão perigosa, uma vez que "um discurso sai a vagar por toda parte, não só entre os conhecedores mas também entre os que não o entendem, e nunca se pode dizer para quem serve e para quem não serve." Sócrates contrapõe a esterilidade do discurso sem cultivador aos discursos que "contêm dentro de si sementes que produzem outras sementes em outras almas".

Jacques Rancière, no prefácio de Políticas da Escrita, apresenta o mito platônico para introduzir a dupla crítica feita à escrita: ser ao mesmo tempo muda e falante demais. Ela é muda porque não há nenhuma voz presente para dar às palavras o "tom da verdade delas, para acompanhá-las de modo a semeá-las no espírito preparado para recebê-las e fazê-las frutificar" (RANCIÈRE, 1995, p. 8); está, portanto, desprovida de legitimidade, de enunciadores e receptores autorizados. É pelo mesmo motivo falante demais, uma vez que qualquer um pode apoderar-se dela e construir uma nova "cena de fala": "a letra morta vai rolar de um lado para o 
outro sem saber a quem se destina, a quem deve, ou não, falar. (RANCIĖRE, 1995, p. 8)"

A escrita seria aquilo que separa o enunciado da voz que o enuncia legitimamente e o leva a destino legítimo, embaralhando as ordens do "fazer, do ver e do dizer". De acordo com Rancière, esta perturbação teórica da escrita tem um nome político democracia: "forma da comunidade repousando sobre a circulação de algumas palavras sem corpo nem pai - povo, liberdade, igualdade... -, que determinam a esfera própria de sua manifestação, afastando qualquer relação 'natural' entre a ordem das palavras e a das condições (RANCIĖRE, 1995, p. 9)".

Tem-se, por outro lado, a "doença da escrita", referente à "desclassificação" que a circulação aleatória do livro e os sonhos que ela alimenta trazem ao curso das existências dedicadas ao trabalho, relegando à contingência qualquer posição legítima da fala e embaralhando a ordem das funções no corpo comunitário. Rancière segue essa linha de pensamento para denunciar a "velha lógica platônica", pela qual a ordem do discurso e a ordem das ocupações sociais selam a comunidade - lógica dos academicismos restaurados do fim do século XX, que "se alimentam e alimentam a ordem existente com a afirmação monótona de que o rigor do pensamento está ligado à divisão estrita das disciplinas e das competências" (CHARTIER, 1990, p. 20).

O mundo da impressão (pressão de um corpo sobre o outro) não é mais o mundo da encarnação. A escrita é, portanto, duas coisas em uma: a própria textura da lei, outrora encarnada na figura do rei; e o regime errante da letra que nenhum enunciador garante. $\mathrm{O}$ mito da palavra perdida seria também, segundo Rancière, $\mathrm{O}$ mito da formação do romance moderno, devido à sua relação singular com a aventura democrática da letra órfã. A fábula de Dom Quixote, o cavaleiro errante, simboliza a modernidade literária, da dispersão da letra "num mundo em que o advento dos poderes da palavra impressa coincide com o apagamento do Verbo encarnado". Rancière diz: "A retirada da promessa da verdade viva é, também, a 
aventura multiplicada dos destinos desviados pelo trajeto da letra sem pai" (CHARTIER, 1990, p. 13/14).

Roger Chartier recorre também à obra de Cervantes para a sua análise das relações entre textualidade e oralidade, ao citar, no ensaio "Textos, impressos, leituras", uma passagem do capítulo XX da primeira parte de Dom Quixote. Nela, Sancho Pança, para passar o tempo numa noite de vigília de armas, narra um cuento de camino ao seu senhor. No entanto, o modo de fazê-lo, "interrompendo frequentemente o relato com comentários e divagações, multiplicando as repetições, projetando o narrador na história e relacionando-a com a situação do momento" (CHARTIER, 1990, p. 125) impacienta seu ouvinte sobremaneira. O fidalgo reclama, insistindo que seu fiel escudeiro narrasse como um "hombre de entendimiento", do contrário seu relato se estenderia por dias. Sancho, entretanto, defende a forma de contar de sua terra e afirma ser esta a única maneira que conhece de fazê-lo. Resignado, Quixote permite que Sancho prossiga: "Di como quisieres". Chartier examina o motivo da frustração do cavaleiro errante:

\footnotetext{
Homem do livro por excelência, para lá dos limites da loucura, Dom Quixote irrita-se com um relato onde não encontra as formas que geralmente lê, e gostaria, no fundo, que a narração de Sancho obedecesse às regras da escrita linear, objetiva, hierarquizada (CHARTIER, 1990,p. 125).
}

Apresenta, assim, as diferenças entre o relato pronunciado e o relato impresso, propondo também uma análise dos atos ou práticas de leitura, cujo objetivo é identificar, para cada época e para cada meio, as "modalidades partilhadas do ler", em um trajeto histórico do texto, do objeto que lhe serve de suporte e das práticas que dele se apoderam. Será a partir desta relação triangular que Chartier irá desenvolver sua reflexão sobre a cultura escrita, na qual iremos nos basear.

\section{Leitores: o vértice do triângulo}

Convém, entretanto, lembrar a advertência feita e repetida por Chartier, bem como por outros pesquisadores do tema, a respeito do vértice deste triângulo, que 
consistiria na recepção do texto, nas práticas de leitura. De acordo com o historiador, esbarra-se aí numa limitação uma vez que se trata quase sempre de um leitor abstrato, universalizado segundo o leitor profissional do século XX. Logo, o conhecimento das práticas plurais de leitura será sempre inacessível, pois nenhum arquivo guarda seus vestígios: "Com maior frequência, o único indício do uso do livro é o próprio livro. Disso decorre também sua imperiosa sedução" (CHARTIER, 1996, p. 103). Citaremos aqui também a ressalva de Robert Darnton que abre o ensaio "A leitura rousseauista e o leitor comum no século XVIII":

\begin{abstract}
a leitura permanece um mistério. Temos dificuldade em compreendê-la hoje e maior dificuldade ainda em nos acercarmos do que era no passado. Não podemos presumir que ela sempre tenha sido para outros o que é para nós atualmente, e nada seria mais perigoso que o anacronismo numa história da leitura (CHARTIER, 1996, p.143).
\end{abstract}

Também a observação de Michel de Certeau: "A leitura não se protege contra o desgaste do tempo (nós nos esquecemos e nós a esquecemos); ela pouco ou nada conserva de suas aquisições, e cada lugar por onde ela passa é a repetição do paraíso perdido". ${ }^{2}$ A leitura de antigamente quase sempre nos escapa.

Uma passagem de Borges no prólogo de Macbeth, entretanto, na qual ele cita o poeta norte-americano Walt Whitman é por sua vez citada por Chartier como estímulo à empreitada: "há um mistério da obra de arte, da beleza absoluta, mas devemos nos aproximar o mais que possamos aos fatos que tornaram possível esse mistério"(CHARTIER, 2002, p.19). O historiador destaca o obstáculo para reconstituir os sentidos próprios de um mundo específico no exemplo: "Platão ou Tucídides compuseram suas obras em um mundo em que todas as práticas se articulam conforme critérios ou gestos que desconhecemos" (CHARTIER, 2001, p.44). E, igualmente, citando Cabrera Infante: "Não se deve esquecer que Góngora escreveu seus sonetos com pena de ganso" (CHARTIER, 2001, p.44). Por isso a ênfase na historicidade das diferenças morfológicas que alteram o significado do que é lido e a

\footnotetext{
${ }^{2}$ Epígrafe do ensaio "Comunidades de leitores", em: $A$ ordem dos livros: leitores, autores e bibliotecas na Europa entre os séculos XIV e XVIII. Brasília: Editora UnB, 1994, p. 11.
}

Texto Digital, Florianópolis, Santa Catarina, Brasil, v. 11, n. 1, p. 263-286, jan./jun. 2015. ISSNe: 1807-9288. 
necessidade de uma consciência das distintas experiências de leitura e das realidades às quais ela se vincula.

Mas, voltemos a Quixote. A passagem mencionada pretende reconstituir por meio da escrita as modalidades de transmissão oral e de apropriação auricular e a tensão entre essa prática antiga e as expectativas do leitor moderno. Sancho Pança conta a história como a contam em sua terra, repleta de digressões, repetições, interrupções e comentários; por sua vez, Dom Quixote fica impaciente, acostumado que está em apreender o texto em sua forma escrita, linear e estável. Estabelece-se dessa forma uma oposição entre o "acontecimento" e o "monumento", entre atuação e inscrição, diferentes registros que organizam a textualidade. A primeira modalidade constitui uma experiência única, efêmera em oposição à estabilidade e a concretude da segunda.

Entretanto, além da passagem do relato oral para o escrito, do "acontecimento" para o "monumento", formas de materialização do texto, há também o percurso da leitura oralizada para a leitura silenciosa, contrapondo a sociabilidade da leitura à privatização do ler e reconstruindo as redes de práticas e gestos que organizam os modos diferenciados de acesso ao texto. Porque as "obras, os discursos, só existem quando se tornam realidades físicas, inscritas sobre as páginas de um livro, transmitidas por uma voz que lê ou narra, declamadas num palco de teatro" (CHARTIER, 2002, p.8). Portanto a necessidade de considerar as trajetórias "da palavra proferida ao texto escrito, da escrita lida aos gestos feitos, do livro impresso à palavra leitora" (CHARTIER, 1990, p. 136).

A leitura em voz alta tinha duas funções predominantes: comunicar o texto aos que não o sabiam decifrar, mas também consolidar as formas de sociabilidade. A leitura em voz alta está em grande medida associada à prática ritual, de um corpo que recebe a palavra sagrada para transmiti-la. Chartier aponta três períodos decisivos desta passagem:

o dos séculos IX-XI, que viram as scriptoria monásticas abandonarem os antigos hábitos da leitura e da cópia oralizada; o do século XIII, com a 
difusão da leitura em silêncio no mundo universitário; e enfim, o da metade do século XIV, quando a nova maneira de ler alcança, tardiamente, as aristocracias laicas (CHARTIER, 1996, p.82).

Contribuiu para isso também a separação das palavras que outrora se encontravam unidas, realizada por escribas irlandeses e anglo-saxões da alta Idade Média (CHARTIER, 1994, p.98), possibilitando a correta divisão das frases e das palavras e o reconhecimento da pontuação sintática. A ausência da separação entre as palavras implicava quase necessariamente em que o leitor lesse em voz alta - caso dos manuscritos em língua latina dos séculos $V$ a VIII. Acreditava-se ser essa uma revolução da leitura, quando leitores, mais hábeis e mais numerosos, adquiriram a capacidade de ler silenciosamente e apenas com os olhos, ao passo que nos primeiros séculos da Idade Média era necessário em grande parte ler em voz alta para se compreender o texto. À nossa maneira contemporânea de ler contrapõe-se uma anterior, dirigida predominantemente ao ouvido:

\begin{abstract}
Ainda no século XVI e XVII, a leitura implícita do texto, literário ou não, constituía-se numa oralização, e seu 'leitor' aparecia como o ouvinte de uma palavra lida. Dirigida tanto ao ouvido quanto ao olho, a obra brinca com formas e procedimentos aptos a submeter o texto a exigências próprias da performance oral (CHARTIER, 1994, p.17).
\end{abstract}

Chartier, no ensaio "A cultura escrita na perspectiva de longa duração" (CHARTIER, 2001), cita o comentário de Borges sobre um famoso texto no qual Santo Agostinho evoca São Ambrósio lendo sem ruminar, sem mastigar as palavras, e espanta-se diante de tal prática silenciosa de leitura, evidência das transformações nos modos de ler. $\mathrm{E}$ até hoje podemos observar essas duas modalidades de leitura associadas a leitores mais ou menos experientes, a relação que os gestos do leitor articulam-se com os textos e sua materialidade.

Em fins do século XVIII, proclama-se uma nova revolução da leitura, que avançaria do "leitor intensivo" para o "leitor extensivo", segundo denominação dicotômica proposta por Rolf Engelsing, como aponta Chartier em Do palco à página. O leitor intensivo seria aquele confrontado com um corpus limitado de livros lidos, relidos, memorizados, transmitidos de geração em geração, numa leitura atenta, com 
frequência em voz alta, carregada de reverência e respeito pelo livro, porque ele é caro e sagrado. Exemplos dessa leitura seriam a da bíblia, das obras de piedade, do almanaque, objetos de manipulações frequentes, de repetidas consultas, de sinalizações familiares.

Por sua vez, a leitura extensiva, moderna, realizada por pessoas instruídas de fins do século XVIII se caracterizaria da seguinte forma:

Ela é a leitura de numerosos textos, lidos em uma relação de intimidade, silenciosa e individualmente. É, também, leitura laicizada, porque as ocasiões de ler se emancipam das celebrações religiosas, eclesiásticas ou familiares e porque se espalha um contato desenvolto com o impresso, que passa de um texto a outro e que não tem mais respeito para com os objetos impressos, amassados, abandonados e jogados (CHARTIER,1996, p. 86).

Em tal consistia o cenário motivador da mudança de um ato de leitura baseado em poucos textos - bem conhecidos, que habitassem o espírito - para uma leitura mais superficial que exigisse menos investimento, baseado em um processo de dessacralização:

\begin{abstract}
a produção impressa e as condições de acesso ao livro em toda a Europa ilustrada sofreram mutações profundas apesar da estabilidade das técnicas e do trabalho tipográficos. Por toda parte, o crescimento da oferta e a laicização dos impressos, a circulação de livros proibidos, a multiplicação dos periódicos, o triunfo dos pequenos formatos e a propagação das salas de leitura e das sociedades literárias, onde a leitura não implicava necessariamente a compra do livro, permitiram e impuseram novas maneiras de se ler. Por outro lado, para os leitores e as leitoras mais letrados, o leque das maneiras de ler parece ter-se diversificado, propondo práticas diferenciadas de acordo com o tempo, os lugares, os gêneros (CHARTIER, 2002, p. 109).
\end{abstract}

As polarizações entre uma literatura comunitária ou individual, intensiva ou extensiva, reverente ou laicizada têm sido contestadas sob o argumento de que à forma "moderna" de leitura coexiste uma "tradicional", de que as práticas funcionam também como índice de diferenciação cultural no interior de uma mesma comunidade, e que as mudanças ocorridas em fins do século XVIII geraram possibilidades de que os atos de leitura se ampliassem em vez de se excluírem: 
“cada leitor podia ser sucessivamente um leitor 'intensivo' ou 'extensivo', absorto ou desenvolto, estudioso ou divertido" (CHARTIER, 2002, p. 109).

Logo, cruzam-se os protocolos de leitura adequados aos diferentes grupos de leitores, em função de suas competências, recursos, preferências, expectativas e particularidades, como observou Chartier:

Da mesma maneira que a oposição entre leitura oral e leitura silenciosa pode ser reconhecida como a expressão das competências que coexistem, a que contrasta duas relações com o impresso deve ser uma primeira, e ainda grosseira classificação das figuras de leitura reencontradas em uma determinada sociedade e praticadas pelos diferentes grupos - sociais, mas também religiosos, intelectuais, étnicos, etc. (CHARTIER, 1998, p. 88/89)

Jean Ranson, o leitor "comum" de Jean-Jacques Rousseau, a partir do qual Robert Darnton conduziu o ensaio já citado aqui, ilustra o modo como essas duas modalidades de leitura antes se cruzaram do que se excluíram. O estudo de Darnton baseou-se em quarenta e sete cartas enviadas por Ranson a Frédéric-Samuel Ostervald, seu antigo mestre no colégio e mais tarde fundador da Sociedade Tipográfica de Neuchâtel (STN), em cujos arquivos ficaram guardadas as cartas, que datam de fins do século XVIII. A primeira indicação colhida é a de que o obscuro provinciano é um leitor exigente no que concerne aos aspectos materiais da obra, tecendo comentários sobre formato, papel e tipografia.

Uma carta de 1774 atesta que Ranson assina vários jornais, os quais lê na companhia de amigos; sete anos mais tarde, outra correspondência aponta que ele desvia-se dos jornais para devotar-se a leituras mais intensivas; além disso, sua paixão pela literatura contemporânea não exclui uma leitura refletida e repetida dos clássicos. Esse diagnóstico põe por terra as separações e entre as categorias de leituras intensiva e extensiva e suas respectivas particularidades: nosso leitor faz o movimento inverso, preterindo as obras de maior densidade ao jornal e é capaz de conciliar dois tipos de leitura que se acreditavam excludentes. 
Mas por que Jean Ranson é o "leitor perfeito" de Rousseau, segundo Darnton? Além de ser um devorador da literatura do filósofo, de interessar-se tanto pela obra como pela vida do autor, Ranson seguia o modelo de leitor visado por Rousseau, aquele para quem os livros participam não apenas da literatura mas também da vida, e isso evidenciou-se no modo como ele relatava a condução de seu casamento e a educação de seus filhos na correspondência com seu mestre. A maneira rousseauista de apropriar-se dos livros consistia em "digeri-los bem", de tal maneira que entrassem profundamente no tecido da vida cotidiana, suprimindo a fronteira que separa literatura e "realidade". Para tanto, era preciso colocar-se na pele dos personagens, "fazer-se solitário, provinciano, estrangeiro, criança". Lia-se para viver - "para noivar, casar-se, educar os filhos" (CHARTIER, 1996, p. 156).

Rousseau quer romper com a literatura tradicional, mostrando-se contrário às belasletras e repudiando o "leitor de sociedade", aquele para quem a leitura persegue um acúmulo exibicionista, na busca de livros que, "como não encontram um tão grande contrapeso exteriormente, têm maior efeito interiormente" (CHARTIER, 1996, p.155). Os procedimentos do autor engendram uma maquinaria cujo efeito máximo é justamente o da "sinceridade", "uma invenção retórica que mascara radicalmente a sua própria existência e postula com êxito a comunicação de coração-a-coração, sem intermediários desviantes" (CHARTIER, 1996, p. 12), como o colocou Alcir Pécora, na introdução à edição brasileira de Práticas da leitura. Logo, quando proclamava-se a revolução da "leitura extensiva", Rousseau desencadeia a mais "intensiva" das leituras, "aquela por meio da qual o romance conquista o seu leitor, o prende e o governa, como antes fazia o texto religioso. (CHARTIER, 1994, p. 100)"

Segundo Darnton, em Práticas da escrita, esse tipo de leitura proposto por Rousseau é o que vai revolucionar a relação entre o leitor e o texto e abrir as vias para o romantismo. Para isso, Rousseau lança mão do que tem sido denominado de "protocolo de leitura", que remonta a certos procedimentos de leitura disseminados pelo texto de modo a assegurar a correta interpretação que se quer dar a ele, na concepção de um "leitor ideal". 
Para Chartier, é preciso considerar conjuntamente a irredutível liberdade dos leitores e os condicionamentos que tencionam refreá-la, de acordo com estratégias dos autores, dos editores, recorrendo a prefácios, glosas, notas, imagens, vinhetas, tipografias bem como a uma retórica que orientasse os passos do leitor. Por exemplo: nas edições impressas de peças de teatro dos séculos XVI e XVII, encontra-se no âmago dos prefácios e prólogos a advertência aos leitores de que aquele texto foi feito originalmente para ser encenado - sua transição para o objeto livro atende a demandas mercadológicas, autorais e de acessibilidade. Naquele momento, há a rejeição da publicação de peças por parte dos dramaturgos, dentre eles Molière, pois estes consideravam que os efeitos teatrais dependiam exclusivamente da representação, de seu modo de transmissão oral e de recepção pelos espectadores. Como consequência, as publicações passaram a trazer gravuras, mostrando cenários e indicações cênicas, procedimentos que visassem alinhar o discurso impresso à performance dramática.

Portanto, podem-se visualizar dois conjuntos de dispositivos: de um lado, os procedimentos de produção de textos; de outro, os de produção de livros. Os primeiros dizem respeito à figura do autor, e às senhas, implícitas ou explícitas, intencionais ou inconscientes que ele inscreve em sua obra e que visam definir o que seria uma relação correta com o texto. De acordo com Chartier, tais procedimentos repousam em uma dupla estratégia de escrita:

inscrever no texto as convenções, sociais ou literárias, que permitirão a sua sinalização, classificação e compreensão; empregar toda uma panóplia de técnicas, narrativas ou poéticas, que, como uma maquinaria, deverão produzir efeitos obrigatórios, garantindo a boa leitura" (CHARTIER, 1996, p.96)

A este procedimento conduzido pelo autor e puramente textual cruzam-se as formas tipográficas, que não pertencem à escrita, mas à impressão, e que são decididas pelo editor-livreiro. Portanto, reconhecer o protocolo inscrito no impresso, que o editor-livreiro supõe para o seu público, é encontrar a inspiração da estética da recepção. 
Fenômeno editorial europeu dos séculos XVII e XVIII, a Biblioteca Azul consistiu em uma fórmula posta em circulação por editores de Troyes - os Oudet e seus rivais Garnier -, na intenção de gerar uma circulação mais ampla de um texto em formato que atendesse às expectativas do público que desejavam atingir, sobretudo rural e popular, fazendo circular no reino livros de baixo preço, impressos em grande número em papel barato e divulgados através da venda ambulante. Pretende-se ganhar um público numeroso, ultrapassando a clientela dos leitores eruditos e notáveis. Decorre disso uma dupla exigência:

de um lado, imprimir com o melhor preço para vender o mais barato possível - o que supõe a utilização de caracteres gastos e de madeira usada, o que multiplica as negligências e gralhas -; de outro, facilitar uma leitura que sabem ser específica e de forma alguma idêntica a dos leitores habituados e virtuosos (CHARTIER, 1990, p.97).

Convém lembrar, como o fez Chartier no ensaio "Textos e edições - a literatura de cordel", que o fenômeno não é exclusivamente francês: na Inglaterra, os chapbooks, também dos séculos XVII e XVIII, são pequenos livros de preço baixo destinados à grande circulação. Na Espanha, é no século XVIII que os pliegos del cordel encontram sua forma clássica: "a de pequenos livros de uma ou duas folhas, e uma difusão maciça, assegurada em parte pelos vendedores ambulantes cegos que cantam seus textos em versos antes de os venderem" (CHARTIER, 1990, p. 165/166). A coleção da Biblioteca Azul, da região de Champagne, na França, por sua vez, distingue-se sobretudo por seu preço - bem mais barato do que os livros comuns mais baratos - e por seu aspecto físico - "é um livro geralmente brochado, geralmente com capa de papel, e de um papel que, na maioria dos casos (mas nem sempre), é azul" (CHARTIER, 1990, p.181).

Uma primeira constatação a respeito dos livros da Biblioteca Azul é que nenhum deles foi escrito originalmente para tal fim editorial. A prática dos editores de Troyes é recorrer ao repertório de textos disponíveis para selecionar dentre aqueles que já tiveram seus direitos autorais expirados os que parecem adequados ao grande público que visam. Daí a extrema diversidade do repertório, que vai buscar elementos em todos os gêneros, em todos os períodos, em todos os estilos, tendo 
em seu catálogo livros de devoção, romances e contos de fadas, obras de utilidade etc. Daí também a distância entre a escrita do texto e sua forma editorial, sua concepção e sua transmissão, distância ao mesmo tempo cronológica e social: "cada um dos textos de que se apodera a Biblioteca Azul visa um leitor implícito que, ao contrário, não está necessariamente de acordo com o comprador sonhado pelos editores de Troyes." (CHARTIER 1996, p. 99) Muitas vezes, o que é contemporâneo ao leitor é o trabalho de edição e não o de escrita, sobrepondo o "leitor implícito" imaginado pelo editor ao "leitor implícito" visado pelo autor. Entretanto, embora por vezes seja grande a distância entre a primeira publicação do texto e sua entrada na Biblioteca Azul, não é apenas de textos antigos que o catálogo sobrevive, os impressores de Troyes são "igualmente ávidos por novidades e apropriam-se de bom grado dos títulos em moda, uma vez expirado o privilégio de seu primeiro editor" (CHARTIER, 1996, p.100).

Além desta particularidade textual, além, é claro, da aparência e preço baixo que conferem unidade aos títulos do catálogo azul, os impressores de Troyes propõem ao seu público textos que compõem uma série, seja pela identidade de seu gênero (vidas de santos, contos de fadas, romances de cavalarias), seja por seu campo de práticas (exercício de devoção, compilação de receitas, livros de aprendizado), seja por sua temática (literatura de mendicância, discurso sobre as mulheres, paródias dos gêneros e das linguagens). Dessa forma, são criadas "redes de textos" que facilitam seu reconhecimento pelo leitor, a partir de estratégias textuais e gráficas manejadas pelo editor no intuito de alcançar aquele leitor que ele tinha em mente ao formular o projeto editorial.

Chartier aponta duas intervenções decisivas sobre o texto operadas pelos editores de Troyes. A primeira visa remodelar a própria apresentação do texto, "multiplicando os capítulos, mesmo que esta divisão não tenha necessidade narrativa ou lógica, e aumentando o número de parágrafos - o que torna menos carregada a distribuição do texto sobre a página" (CHARTIER,1996, p.101). Há, nessa divisão, que reparte o texto em capítulos, que engendra mecanismos de retorno à narrativa, como que uma inscrição no livro daquilo que os editores pensam ser sua leitura: uma leitura que 
não é virtuosa nem contínua, mas que toma e deixa o livro, que apenas decifra facilmente sequências breves e fechadas, que exige sinalizações explícitas. A segunda intervenção editorial sobre os textos pressupõe uma leitura capaz de apreender somente enunciados simples, lineares, cerrados.

Logo, a distância entre os textos das edições "eruditas" e os textos das edições azuis traduzem a maneira como os impressores de Troyes concebiam seu "leitor implícito", evocando sempre as necessidades comerciais da edição barata que supõem baixos preços de custo e pouca exigência. Essa estética da recepção, no entanto, oscila entre duas perspectivas: a que considera que os dispositivos textuais ou gráficos impõem uma necessária leitura da obra; e a que reconhece a pluralidade das leituras possíveis de um mesmo texto, em função das disposições individuais, culturais e sociais de cada leitor. Assim, estabelece-se uma distância entre o leitor ideal, proposto pelo autor ou editor, e o leitor real, quase sempre inacessível.

Expressão semelhante a "protocolo de leitura" e do mesmo campo de "estética da recepção" é utilizada por Chartier: "ordem dos livros". Diz o historiador: "O livro sempre visou instaurar uma ordem; fosse a ordem de sua decifração, a ordem no interior da qual ele deve ser compreendido ou, ainda, a ordem desejada pela autoridade que o encomendou e permitiu a sua publicação". Com a ressalva: "Todavia, essa ordem de múltiplas fisionomias não obteve a onipotência de anular a liberdade dos leitores" (CHARTIER,1994, p.8). Como notou Alcir Pécora, para Chartier a "ordem dos livros" está à frente da "ordem dos discursos", e ainda à frente desta estaria a desordem de seus usos. Chartier coloca assim a questão: "Nenhuma ordem dos discursos é, de fato, apartável da ordem dos livros que the é contemporânea." (CHARTIER,1996, p.106).

Mas, afinal, orientação ou armadilha, liberdade ou imposição?, lança a pergunta Chartier para assinalar a necessidade de se reunir duas perspectivas frequentemente separadas: "o estudo da maneira como os textos e os impressos que Ihes servem de suporte organizam a leitura que deles deve ser feita e, por outro lado, a recolha das leituras efetivas, captadas nas confissões individuais ou 
reconstruídas à escala das comunidades de leitores" (CHARTIER,1990, p.124). Para tanto, Chartier sugere a noção de "apropriação" a fim de superar antigas divisões massificadoras que reduzissem os atos de leitura à sua "estratificação social", nisso confundindo o "social" exclusivamente com a hierarquia das fortunas e das condições. Uma vez que diversos são os exemplos de empregos "populares" de objetos, de ideias e de códigos não considerados como tais, aponta ele, é preciso reconhecer as práticas partilhadas que atravessam os horizontes sociais. Logo, "apropriação" como noção que permite pensar as diferenças fora de uma divisão dicotômica hierárquica e que postula a invenção criadora no próprio cerne dos processos de recepção.

Aposta-se na maneira contrastante pela qual os grupos ou os indivíduos fazem uso dos motivos ou das formas que partilham com os outros e considera-se a história dos textos e dos livros como a reconstituição das distâncias nas práticas, ou seja, uma história dos atos de ler. Para Chartier, isso equivale a dizer, simultaneamente, que "as práticas contrastantes devem ser entendidas como concorrências, que as suas diferenças são organizadas pelas estratégias de distinção ou de imitação e que os empregos diversos dos mesmos bens culturais se enraízam nas disposições do habitus ${ }^{3}$ de cada grupo" (CHARTIER,1990, p.137).

Sendo assim, "disciplina" e "invenção"; "distinção" e "divulgação", esta entendida não apenas pelo processo de difusão, mas também de vulgarização e imitação. 0 segundo par aponta para uma "luta de concorrência" em que toda divulgação, concedida ou conquistada, produz imediatamente a procura por uma nova distinção. Chartier usa como exemplo o livro para mostrar como isso funciona: quando o livro se torna um objeto menos raro, menos confiscado, menos distintivo pela sua própria posse, "são as maneiras de ler que se encarregam de mostrar as distâncias, de manifestar as diferenças socialmente hierarquizadas" (CHARTIER,1990, p. 138).

\section{O livro impresso e o homem moderno}

\footnotetext{
${ }^{3}$ Noção de Norbert Elias. 
E para falar da disseminação do livro, de sua democratização, é preciso introduzir a próxima revolução, que seria a da invenção dos tipos móveis - caracteres metálicos em relevo - e da prensa por Gutenberg em meados da década de 1450 e o impacto das formas do impresso na cultura ocidental:

\begin{abstract}
Por um lado, fixam ou são portadoras da palavra, cimentam as sociabilidades e prescrevem os comportamentos, atravessam o foro privado e a praça pública, levam a crer, a fazer ou a imaginar: revolvem a cultura na sua totalidade, compondo com as formas tradicionais da comunicação, instaurando novas distinções. Por outro lado, permitem uma circulação da escrita numa escala inédita, tanto porque a impressão baixa o custo de fabrico do livro, doravante repartido por todos os exemplares de uma mesma tiragem, e já não suportado por uma única cópia, como porque ela encurta os prazos da produção, muito longos nos tempos do livro manuscrito. (CHARTIER, 1996, p. 138/9)
\end{abstract}

Uma revolução, em primeiro lugar, técnica, promovendo a passagem de uma cultura em que a forma de reprodução dos textos se dava pelo manuscrito para uma cultura do impresso, cujo poder multiplicador, de penetração e irradiação foi propulsor da cultura moderna e da indústria do livro. O livro sai de uma esfera de produção artesanal, na qual "cada caráter, linha e página eram compostos à mão por complicados processos, em que o artesão deixava as marcas de sua individualidade" (CHARTIER, 1996, p.149), para se tornar um objeto de produção e consumo de massa. Acentua-se aí também a distância entre a caligrafia do autor ou copista e a letra romana que se tornou o caractere dominante nos livros impressos.

curioso é que o avanço desta mesma técnica, que permitiu à literatura distanciarse do estatuto dos textos medievais, configurando-se como um campo de prestígio e poder, foi sendo percebido, ao longo do tempo, como ameaça à sua sobrevivência, pela possibilidade que a técnica encerrava, como apontou Vera Follain de Figueiredo: "(a mesma técnica que lhe deu origem) de fazê-la voltar à indiferenciação, de dissolvê-la num meio de circulação de discursos não hierarquizados". Amplia-se, portanto, a tensão entre distinção e divulgação, "constitutiva do que se convencionou chamar de literatura" (FIGUEIREDO, 2010, p.65). 
O impacto desta nova tecnologia gerou repercussões tão grandiosas quanto a popularização do protestantismo - pois foi através dos impressos que as ideias reformistas de Lutero puderam se expandir -, a consolidação das línguas nacionais - quando o Evangelho passou a ser veiculado em idioma popular - e, ao fim e ao cabo, a sedimentação da ideia do que se convencionou chamar o "homem moderno". Desde Gutenberg, toda a cultura ocidental pode ser considerada a cultura do impresso uma vez que este, em sua relação com a escrita, passou a fazer parte da totalidade das práticas culturais, em cartazes, inscrições, livros, éditos ou textos oficiais colados nas paredes, "incluindo as que não são de leituras, como as rituais ou as de festas, e incluindo a população analfabeta ou mal alfabetizada" (CHARTIER, 2001, p.35).

A cultura do impresso, que é também a cultura da escrita, confrontou-se desde os primórdios e durante muito tempo com três inquietações. A primeira é o temor da perda, que levou "à busca dos textos ameaçados, à cópia dos livros mais preciosos, à impressão dos manuscritos, à edificação das grandes bibliotecas" (CHARTIER, 1998, p.15). Contra o desaparecimento e o esquecimento dos textos, trata-se de recolhê-los, fixá-los, preservá-los. A segunda ameaça é a da corrupção, se antes pela mão do escriba que pode falhar e acumular erros, então pela ignorância dos tipógrafos ou dos revisores, ou pelos maus modos dos editores. Última inquietude: a do excesso - de uma "sociedade completamente invadida por seu patrimônio escrito e pela impossibilidade de que cada indivíduo maneje e domestique esta abundância textual" (CHARTIER, 2001, p.21). Para dominá-la, seriam necessários instrumentos e estratégias capazes de triar, classificar, hierarquizar, numa ideia de redução desenvolvida por meio do trabalho da construção dos cânones dos textos clássicos, por meio da crítica, pela escola, pelos poderes, a fim de facilitar o "encontro feliz" entre aquilo que o livro quer dizer e o que determinados leitores desejam ler. Três temores que, por oposição, demarcam três funções primordiais do objeto livro: de conservação, rigor e multiplicação.

Contudo a transformação não é tão absoluta como se diz, ressalta Chartier, negando que a revolução da imprensa consistisse na "aparição do livro". O historiador 
argumenta que um livro manuscrito e um livro pós-Gutenberg baseiam-se nas mesmas estruturas fundamentais - as do códex:

\begin{abstract}
Tanto um como outro são objetos compostos de folhas dobradas um certo número de vezes, o que determina o formato do livro e a sucessão dos cadernos. Estes cadernos são montados, costurados uns aos outros e protegidos por uma encadernação. A distribuição do texto na superfície da página, os instrumentos que lhe permitem as identificações (paginação, numerações), os índices e os sumários: tudo isto existe desde a época do manuscrito (CHARTIER, 1998, p.9).
\end{abstract}

O argumento de Chartier evidencia o método segundo o qual ele aborda a história do livro e das práticas de leitura, na compreensão de que o texto não existe unicamente na sua realidade semântica, alheia à realidade material: formato, imagens, capa, margens constituem elementos que importam no processo de construção do sentido - esta encarnação do texto numa materialidade específica carrega as diferentes interpretações, compreensões e usos de seus diferentes públicos.

Nessa perspectiva, Gutenberg e sua invenção teriam um papel matizado, uma vez que os gestos do leitor seriam similares àqueles diante do códice, forma que permaneceu própria na cultura do impresso e cuja revolução aconteceu nos séculos II, III e IV da era cristã, substituindo o volumen, o livro em forma de rolo, utilizado pelos egípcios desde por volta de 2.700 a 2.400 a. C.

No rolo, uma longa faixa de papiro ou de pergaminho aberto horizontalmente a partir de uma vara de madeira, escrevia-se na parte interna, dispondo as linhas em colunas. Logo, ler um rolo implica uma prática completamente diferente daquela de ler um códice ou um livro moderno, pois o texto corre diante dos olhos do leitor e este tem as duas mãos detidas nas réguas de madeira, impedindo o ato de ler e escrever ao mesmo tempo, daí também a importância do ditado em voz alta.

A leitura do códice, por sua vez, proporciona maior liberdade ao leitor: "colocado numa mesa ou púlpito, o livro reunido em cadernos já não exige uma total mobilização do corpo, proporciona maior independência ao leitor, que pode ler e 
escrever ao mesmo tempo, passar, a seu bel prazer, de uma página a outra, de um livro a outro" (CHARTIER,1994, p.102). O leitor do livro em forma de códex coloca-o diante de si sobre uma mesa, vira suas páginas ou então o segura quando o formato é menor e cabe nas mãos, e sua mão pode escrever sobre a página notas e indicações marginais.

A utilização dos dois lados do suporte reduz o custo de fabricação do livro, ademais permite reunir uma grande quantidade de texto num volume menor. Além disso, o códice possibilita uma melhor localização do texto, agilizando seu manejo: "possibilita a paginação, a criação de índices e concordâncias, a comparação de uma passagem com outra, ou, ainda, permite ao leitor que o folheia percorrer o livro por inteiro" (CHARTIER, 1994, p.102).

O formato do códice é herdado por Gutenberg, bem como a hierarquia que se estabelece entre gêneros e formatos, tipos de livros e categorias de discursos e, assim, instala-se um sistema de localização e identificação dos textos:

\footnotetext{
o grande in-fólio que se põe sobre a mesa é o livro de estudo, da escolástica, do saber; os formatos médios são aqueles dos novos lançamentos, dos humanistas, dos clássicos antigos copiados durante a primeira voga do humanismo, antes de Gutenberg; e o libellus, isto é, o livro que se pode levar no bolso, é o livro de preces e de devoção, às vezes de diversão" (CHARTIER, 1998, p.08/09)
}

Portanto assinala-se uma continuidade muito forte entre as culturas do manuscrito e do impresso, embora durante muito tempo tenha se acreditado em uma ruptura total entre elas. Por isso, convém lembrar, como fez Chartier em Desafios da escrita, que "insistir na importância que manteve o manuscrito após a invenção de Gutenberg é uma forma de lembrar que as novas técnicas não apagam nem brutal nem totalmente os antigos usos" (CHARTIER,2002b, p.8). Também somos lembrados por Chartier que, de modo geral, persistia uma forte suspeita diante do impresso, que "supostamente romperia a familiaridade entre o autor e seus leitores e corromperia a correção dos textos, colocando-os em mãos 'mecânicas' e nas práticas do comércio" (CHARTIER,1998, p.09). 
Problematiza-se, dessa forma, o emprego do termo "revolução", algumas vezes citado aqui, geralmente na esteira das reflexões de Chartier e por ele também relativizado, uma vez que antigas práticas invariavelmente convivem com novas e raramente as substituem totalmente, sem que com isso se minimizem os efeitos que tais transformações produziram. Uma forma de olhar para isso, como Chartier nos propõe, é a partir de linhas distintas de transformações. Tem-se a linha de transformação relacionada à história da leitura, que teve dois momentos importantes: a passagem da leitura oralizada para a silenciosa, quando o leitor prescindiu da necessidade de oralização para entender o que lê; e o que se chamou de "revolução da leitura" do século XVIII, quando da leitura intensiva se passa para a extensiva. Há, também, a linha de transformação das técnicas de reprodução de textos, quando se passou de uma técnica manual a uma técnica baseada na composição por caracteres móveis e na impressão pela prensa, na qual o papel de Gutenberg é nada menos do que essencial. Em seguida, a linha de transformação do livro, que não é vinculada a de Gutenberg, uma vez que se mantiveram as mesmas estruturas fundamentais do livro; seu primeiro momento-chave é, pois, nos séculos II, III e IV da era cristã, com a invenção do códice e, em seguida, como afirma Chartier, com a invenção de um novo suporte do texto escrito radicalmente original: a tela, "outra forma de livro, pois pode-se falar também do livro eletrônico" (CHARTIER, 2001, p.39).

"A revolução do nosso presente é mais importante do que a de Gutenberg, ela não somente modifica a técnica de reprodução do texto, mas também as estruturas e as próprias formas do suporte que o comunica aos seus leitores" (CHARTIER, 1994, p.97). A afirmação de Chartier, no ensaio "Do códex à tela: as trajetórias do escrito", evidencia a radicalidade das transformações nas modalidades de produção, de transmissão e recepção do escrito decorrentes da "revolução" digital da segunda metade do século XX. Logo, as transformações do livro a que assistimos atualmente teriam um único precedente na história ocidental: a passagem do volumen para o códex. 
O livro como o conhecemos há aproximadamente dezoito séculos, com seus cadernos, sua capa, suas páginas, que podemos manusear, folhear, carregar não mantém sua estrutura e materialidade na virtualidade do livro eletrônico: "à captura imediata da totalidade da obra, tornada visível pelo objeto que a contém, ela faz suceder a navegação de longo curso entre arquipélagos textuais sem margens nem limites" (CHARTIER, 1994, p.101). Perde-se a corporeidade do objeto livro em favor da imaterialidade dos textos sem lugar específico, dispostos na "rede virtual", na "nuvem" da numerização dos discursos, acessível a quem detiver um aparelho eletrônico que o decodifique e a habilidade de manuseá-lo. Assim, anula-se a coincidência, até então indispensável, entre o lugar do texto e o lugar do leitor.

Além disso, acrescentam-se possibilidades de novas formas narrativas a partir do hipertexto e da utilização simultânea de diferentes linguagens - letras, imagens, sons -, que muitas vezes borram os limites entre o autor e o leitor, em detrimento da autoridade do primeiro, ao mesmo tempo que diminuem ou mesmo eliminam o papel do editor, nos exemplos da autopublicação, de modo que as operações podem ser acumuladas e tornadas contemporâneas. Enquanto o objeto impresso impunha uma forma materialmente fechada, na qual o leitor podia inscrever sua presença apenas sub-repticiamente, nas margens, na folha de rosto, nas entrelinhas, o suporte eletrônico propõe ao leitor uma maior liberdade operatória a fim de que se ampliem materialmente e textualmente as possibilidades do livro. A concepção do texto como intertexto contrapõe-se à ideia da obra como objeto finito, fechado após sua conclusão, ao mesmo tempo que valoriza sua exterioridade, em oposição à restrição da obra que deve ser avaliada como circuito interno. Tais possibilidades interrogam a noção de autoria, estabelecida no século XVIII, como um ato de criação individual, colocando em risco o direito em torno da propriedade literária.

Por outro lado, o texto eletrônico aproxima da realidade o "antigo sonho" de uma biblioteca universal que contivesse todos os títulos do mundo, superando a realidade profundamente decepcionante de "coleções que, por maiores que sejam, nada podem fornecer além de uma imagem parcial, lacunar, mutilada, do saber universal" (CHARTIER, 1994, p.105), com o prejuízo do temor pelo excesso, porém com a 
"felicidade extravagante" da qual fala Borges, prometida pelas "bibliotecas sem paredes, e mesmo sem endereço, que serão aquelas do nosso futuro" (CHARTIER, 1994, p.105).

No entanto, se por um lado Chartier enaltece as imensas possibilidades inauguradas pelo novo suporte, por outro alerta para a inevitável "violência" contra os textos separados de suas materialidades originais, que contribuíram para construir suas significações, e para o risco de se perder a inteligibilidade de uma cultura textual em que a ordem dos discursos estava vinculada a uma forma particular de livro: o códex.

E, embora seja perigoso fazer afirmações ou delimitar uma "revolução" que ocorre no contexto contemporâneo, algumas considerações podem ser feitas sobre a nova materialidade que encarna o texto, tendo em vista, no entanto, que este é apenas o modelo paradigmático e bastante simplificado que se retém e que convive com a forma anterior, no caso ainda majoritariamente os impressos, e também com "híbridos" nos quais se combinam diferentes propostas de apresentação. O que se destaca aqui é a pluralidade de existências do texto que se verifica em sua trajetória histórica, estritamente dependente de sua forma material, seja pela palavra oral, pelas artes dramáticas, pelo livro em rolo, em códice, pelo livro eletrônico ou "quaisquer mídias a serem criadas nos próximos sete anos", como aparece nos contratos de algumas editoras atualmente.

Inovações técnicas que transformaram o suporte do texto e sua forma de reprodução criaram condições para que se constituísse o que hoje chamamos de literatura e de instituição literária, que seria, segundo Chartier, a consolidação do conceito de obra, com seus critérios de unidade, coerência e estabilidade; a categoria de autor, que atribui à obra literária a um nome próprio; e finalmente, o comentário que identificado com o trabalho de interpretação, revela os significados da obra (CHARTIER, 2002, p.21/22). Hoje vemos que tais categorias não são mais tão estáveis quanto se pretendia, e que o conceito de literatura repousa sobre uma 
indeterminação cujos limites não param de se apagar, sem que isso, no entanto, constitua necessariamente uma ameaça à sua sobrevivência.

\section{MATERIALITY OF THE TEXT: A HISTORICAL PATH}

SUMMARY: This article will focus in the matter of the materiality of the text and its supports, which can't be disconnected from its condition of production, transmission and reception. To approach such matter, we will put in dialogue the thoughts of Jacques Rancière and Roger Chartier. The first one begins with the platonic myth of Fedro to fix the double critic towards the writing: being at once mute and talkative, and focus in the nostalgia of the presence, the orphan letter in search of a father, a body in which to incarnate. Chartier, by its turn, puts emphasis in the transformations of the reading practices in the trajectory from the roll to the codex and in the most recent revolution that would consist in the new support represented by the screens.

KEY-WORDS: Writing. Support. Materiality. Author.

\section{Referências}

CHARTIER, Roger. A história cultural - entre práticas e representações. Trad. de Maria Manuela Galhardo. Rio de Janeiro: Editora Bertrand Brasil, 1990.

A ordem dos livros: leitores, autores e bibliotecas na Europa entre os

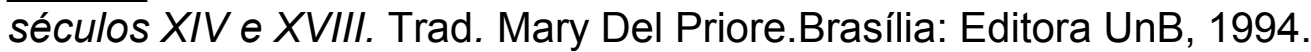

- Práticas da leitura. Trad. Cristiane Nascimento. São Paulo: Estação Liberdade, 1996.

A aventura do livro - do leitor ao navegador. Trad. Reginaldo de Moraes. São Paulo: Editora Unesp, 1998.

. Cultura escrita, literatura e história. Trad. Ernani Rosa. Porto Alegre: Artmed Editora, 2001.

. Do palco à página - Publicar Teatro e Ler Romances na Época moderna

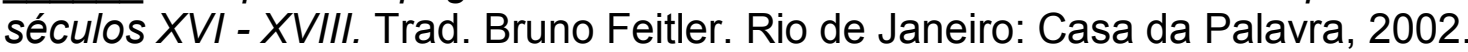

Unesp, 2002b.

Os desafios da escrita. Trad. Fulvia M. L. Moretto. São Paulo: Editora

DARNTON, Robert. "A leitura rousseauista e um leitor 'comum' do século XVIII". In: CHARTIER, Roger (Org.). Práticas da leitura. Trad. Cristiane Nascimento. São Paulo: Estação Liberdade, 1996. p. 143-176.

ECO, Umberto. Obra aberta. Trad. Giovanni Cutolo. São Paulo: Perspectiva, 1991. 
2009.

. Não contem com o fim do livro. Trad. André Telles. Rio de Janeiro: Record,

FIGUEIREDO, Vera Follain de. Narrativas migrantes: literatura, roteiro e cinema. Rio de Janeiro: Ed.PUC-Rio: 7 letras, 2010.

RANCIĖRE, Jacques. Políticas da escrita. Trad. Raquel Ramalhete et al. São Paulo: Editora 34, 1995.

STEINER, George. Nenhuma Paixão Desperdiçada. Trad. Maria Alice Máxima. Rio de Janeiro: Record, 2001.

Texto recebido em: 26/02/2015.

Texto aceito em: 29/04/2015. 